\title{
Rare Anomaly of a Single Coronary Artery Arising from the Right Aortic Sinus of Valsalva: A Case Report
}

\author{
Kassem Farhat ${ }^{1}$, Jean Dib ${ }^{1}$, Antoine El Khoury ${ }^{2}$, Alain Asmar ${ }^{3}$ \\ ${ }^{1}$ Faculty of Medical Sciences, Lebanese University, Hadath, Lebanon \\ ${ }^{2}$ Department of Cardiology, University of Balamand Faculty of Medicine, Beirut, Lebanon \\ ${ }^{3}$ Department of Cardiology, Notre Dame University Hospital, Jounieh, Lebanon
}

Corresponding Author: Kassem Farhat, Zalka, Lebanon, kassem.farhat93@hotmail.com

Notre Dame University Hospital, Jounieh, Lebanon

Financial support: None

Conflict of Interest: None

Consent: Written informed consent was obtained from the patient for publication of this case report and accompanying images.

\begin{abstract}
Background: Single Coronary Artery (SCA) is a rare, most commonly asymptomatic, congenital anomaly which is usually discovered incidentally during investigations. This entity consists of a single coronary artery supplying the entire myocardium. It may be classified based on the origin and the course of the artery. Depending on the patient's presentation and its severity, medical or invasive interventions may be warranted.

Case Report: A 65-year-old female patient known to have diabetes and hypertension presented to our emergency department with chest pain and discomfort. Blood tests and electrocardiography (ECG) showed no significant abnormalities, but on coronary angiography, we suspected an anatomical variation. Computed tomography angiography (CTA) confirmed our suspicion revealing a single coronary artery supplying the entire myocardium and arising from the right sinus of Valsalva. The patient received medical therapy and was discharged home.

Conclusion: We presented this case of Single Coronary Artery due to the rarity of this diagnosis. Presentation, treatment plan, and prognosis typically vary depending on the subtype of the anomaly. Early recognition is very important, especially in young adults.

Keywords: Single coronary artery, congenital heart disease, left circumflex artery, left anterior descending artery, right ostium, chest pain, case report
\end{abstract}

\section{Background}

SCAs are rare congenital anomalies usually identified incidentally during coronary angiography (CA), upon presentation with different kinds of symptoms, or postmortem after sudden cardiac arrests in young athletic adults. Such anomalies were first described over a century ago. They consist of a unique coronary artery supplying the entire myocardium from a single coronary ostium. Incidence varies among different populations, from 0.014 to $0.066 \%$ in 
populations undergoing angiography, and up to $0.3 \%$ in autopsy series [1-4].

We report the case of an elderly lady presenting with angina that turned out to be associated with a single right coronary artery supplying the entire myocardium.

\section{Case Presentation}

A 65-year-old female known to have hypertension and type 2 diabetes mellitus, presented for a twoweek history of retrosternal chest pain associated with severe dyspnea on mild exertion. Vital signs were normal and physical examination was significant for bilateral lower limb pitting edema. The electrocardiography (ECG) showed evidence of a left bundle branch block (LBBB) with STdepression in leads I, aVL, V5, and V6. There were no new changes in comparison with previous ECGs. Cardiac markers (Creatine phosphokinase $\mathrm{CPK}$, creatine kinase myocardial band CPK-MB, and troponin I) were negative on serial measurements. Subsequently, acute coronary syndrome treatment was not given. Chest radiography showed no relevant findings. Coronary angiography showed significant stenosis at the level of the second segment of the right coronary artery (RCA) and the origin of the posterior interventricular artery, without opacification of the left coronary circulation, despite multiple attempts (Fig. 1). Echocardiography revealed a left ventricular ejection fraction (LVEF) of $35 \%$. Computed Tomography Angiography (CTA) showed aberrant coronary anatomy with the left main coronary artery (LMCA) arising from the right ostium, passing anterior to the pulmonary trunk, and dividing into 2 branches: The Left Anterior Descending artery (LAD) and Left Circumflex Artery (LCX) (Fig. 2-3). Percutaneous Coronary Intervention ( $\mathrm{PCl}$ ) was deemed risky and the patient was instead managed with dual antiplatelet therapy, anti-anginal medications, and a statin. Her clinical status stabilized, and she was discharged home.

\section{Discussion}

SCAs are rare congenital anomalies that go unnoticed until adulthood and in some cases until the fifth or sixth decades of life. They consist of a single coronary artery supplying the entire myocardium. The reported incidence of SCAs is variable and ranges between 0.014 and $0.066 \%$ of the population [5-11]. Turkmen et al. reviewed 215,140 patients referred for angiography and found that $0.031 \%$ had SCAs [8]. Yamanaka et al. reported an incidence of $0.045 \%$ out of 126,595 patients [10], and Tuncer et al. reported an incidence of $0.014 \%$ out of 70,850 patients (Table 1) [7]. Desmet et al. reviewed 50,000 cases and found thirty-three cases of SCAs or an incidence of $0.066 \%$ [3].

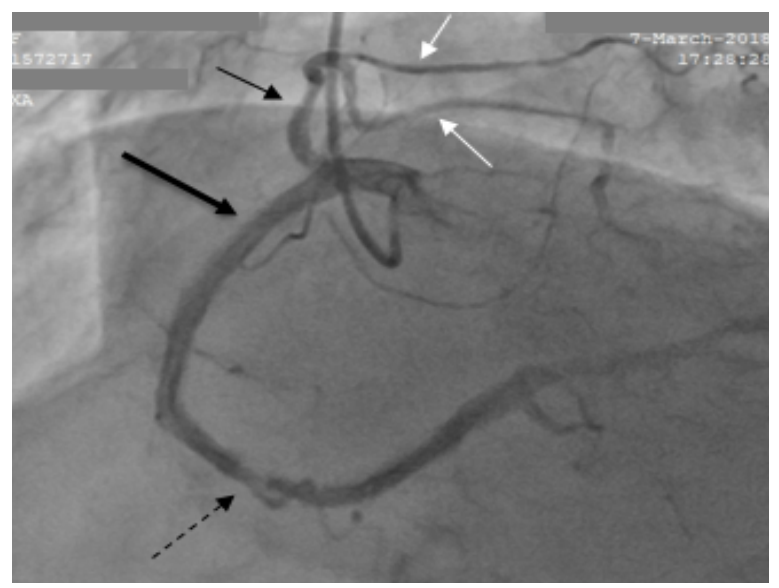

Figure 1: Conventional coronary angiogram following injection into the single right coronary ostium shows a hyper-dominant RCA (thick black arrow), focal stenosis at the level of the second segment of the RCA (dashed arrow), LMCA arising from the right ostium (thin black arrow) and giving rise to $L A D$ and $L C X$ (white arrows)

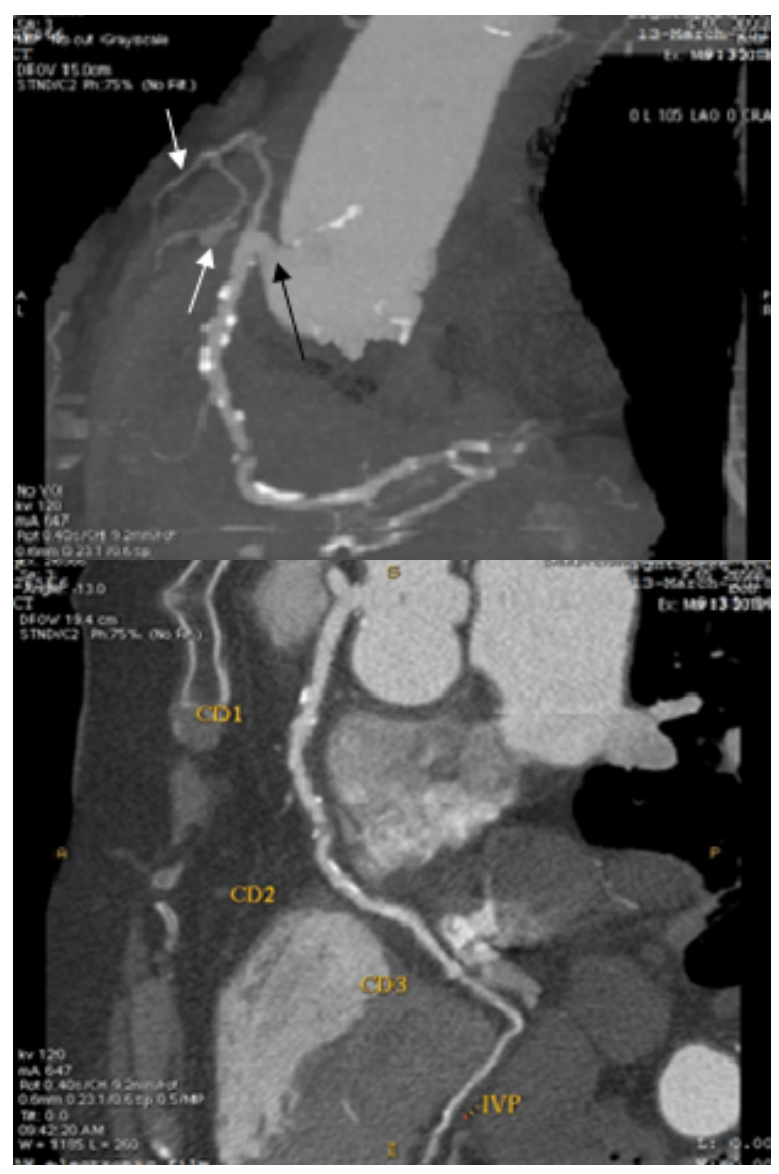

Figure 2: Transverse section demonstrating the long transverse course of the left coronary artery to the pulmonary artery with the LMCA arising from the right aortic sinus of Valsalva (black thin arrow), and branching into LCX and LAD (white thin arrows). 


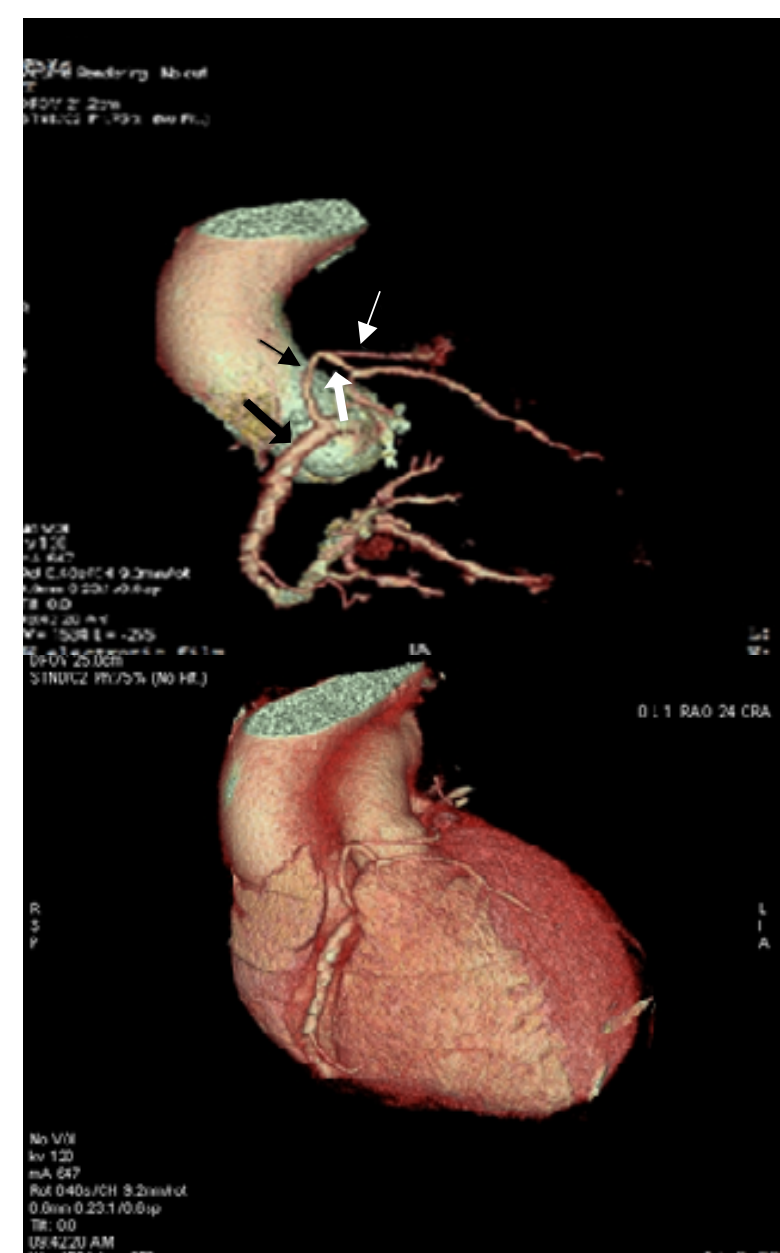

Figure 3: Three-dimensional volume-rendered reformations. Single coronary artery arises from the right coronary sinus. It bifurcates into a normally coursed dominant right coronary artery (thick black arrow), and an anomalous left main coronary artery (thin black arrow). The LMCA bifurcates into LAD and LCX (white thick and think arrows respectively).

SCAs may be associated with other cardiac abnormalities including Tetralogy of Fallot, pulmonary artery defects, coronary arteriovenous fistulae, transposition of the great arteries, bicuspid aorta, and patent ductus arteriosus [1213]. Kervancıoğlu et al. found that SCAs were present in $3.5 \%$ of patients with Tetralogy of Fallot [5]. There is no gender preference with SCAs, however, most large series review patients presenting for coronary angiography, and therefore, the reported incidence may be different from the general population. The most dramatic picture of SCAs is when young athletes present with sudden death during strenuous exercise [1416].

Atypical chest pain or non-specific symptoms, syncope, heart failure, arrhythmias, dyspnea on exertion, palpitations, ventricular tachycardia, and myocardial infarction or sudden cardiac death, have been reported as presenting symptoms. In the Turkmen et al. series, $4.5 \%$ of the patients presented with myocardial infarction. The majority of these patients did not turn out to have critically stenosed coronaries [8].

Significantly severe symptoms like angina, syncope, or sudden cardiac arrest are usually seen when the SCA courses between the aorta and pulmonary arteries where it is subjected to kinking and compression, especially during exertion when the arterial diameter grows [17, 18]. Heavy exercise is one of the main triggers of death in such patients. A study of 242 deceased patients with isolated congenital coronary anomalies showed that one-third suffered from sudden cardiac death, and half of these were exercise-related; patients younger than 30 years are more likely to suffer from sudden cardiac death during physical exertion [19].

Lipton et al. were the first to propose a classification of SCAs (Fig. 4) [2]. Other authors like Yamanaka et al. added some modifications to this classification (Table 2) [10]. The origin of the SCA from the ostia is designated with $R$ for right ostium and $L$ for left ostium. Since SCAs may have different origins and different courses, this letter is followed by a roman numeral that describes the course. Class I is when the SCA follows the anatomical course of the normal Right Coronary Artery (RCA) or Left Coronary Artery (LCA). Class II describes a normally arising SCA from the proximal part of the ostium that reinserts into the mid or distal LAD, feeding the proximal LAD and Circumflex arteries. In Class III, the LAD and LCX arise from separate coronary trunks. This Roman numeral is followed by a letter describing the course of the transverse branch as follows: (A) anterior to the large vessels, (B) between the Aorta and Pulmonary artery, $(P)$ posterior to the large vessels, $(S)$ passing over the interventricular septum, or (C) combined (Table 2) $[2,10,16,20]$.

The majority of patients with SCAs are of the RI, LI, and RIIA types. These subtypes have a benign course with symptoms arising, at times, from coronary atherosclerotic lesions [21]. In cases where the SCAs originate from the contralateral sinuses and travel between the large trunks, such as in RIIB, LIIB, and RIII, more serious clinical courses can occur. The large trunks dilate during exercise, when the demand is high, which results in compression of the SCAs [21]. Therefore, the inter-arterial course $(B)$ is the one associated with the worst outcomes. Additionally, slit-like orifices, unusual SCA take-off angles, and kinked compressible courses are predisposing features 
Turkmen et al. 215,140 patients

\begin{tabular}{|r|c|c|c|}
\hline Total Incidence & $0.031 \%$ & $0.045 \%$ & $0.014 \%$ \\
\hline R-I per 100,000 & 2.6 & 0.79 & 1.4 \\
\hline R-II per 100,000 & 10 & 15 & 4.2 \\
\hline R-III per 100,000 & 4.3 & 3.9 & 4.2 \\
\hline L-I per 100,000 & 7 & 15.8 & 2.9 \\
\hline L-II per 100,000 & 5.2 & 8.7 & 1.4 \\
\hline
\end{tabular}

Table 1: Summary of 3 large series on SCAs incidence $[7,8,10]$

Classification

\begin{tabular}{|c|l|}
\hline$R I$ & $\begin{array}{l}\text { SCA originating from the RCC, following the } \\
\text { course of RCA or LCA }\end{array}$ \\
\hline LI & $\begin{array}{l}\text { SCA originating from the } L C C \text {, following the } \\
\text { course of RCA or LCA }\end{array}$ \\
\hline RII & $\begin{array}{l}\text { SCA arising from the RCC, feeding the mid } \\
\text { and distal LAD and mid LCX }\end{array}$ \\
\hline LII & $\begin{array}{l}\text { SCA arising from the LCC, feeding the mid } \\
\text { and distal LAD and mid LCX arteries }\end{array}$ \\
\hline RIII & $\begin{array}{l}\text { SCA arising from the RCC and feeding the } \\
\text { LAD and LCX from separate coronary trunks }\end{array}$ \\
\hline
\end{tabular}
Yamanaka et al. Tuncer et al. 70,850 patients 


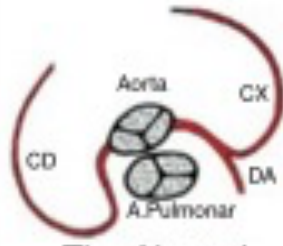

Tipo Normal

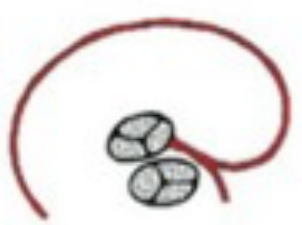

LI

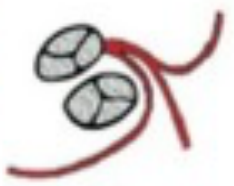

LII-A

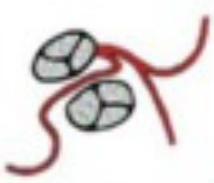

LII-B

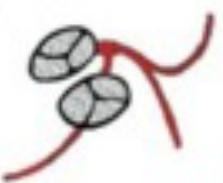

LII-S

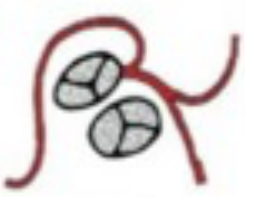

LII-P

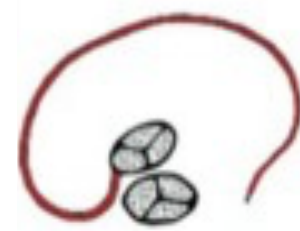

RI

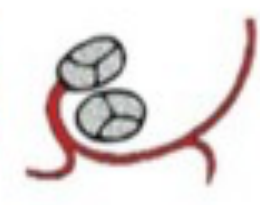

R II-A

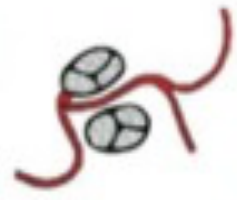

R I-B

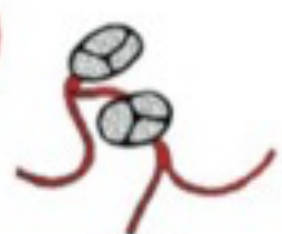

R II-S

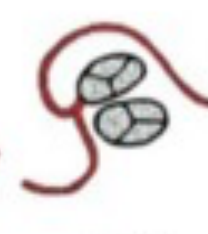

R II-P

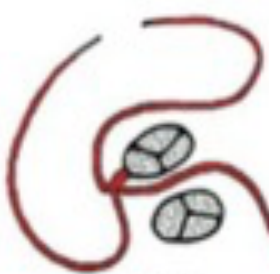

R III

Figure 4: Lipton's classification of single coronary artery. Figure retrieved from Neiva et al. [35]

to different symptoms of ischemia or sudden death. About $15 \%$ of patients with detectable exercise-induced ischemia may have those abnormalities [10, 22, 23]. Our case is of the RIIA subtype, where the SCA arises from the right sinus of Valsalva, courses anterior to the large vessels, and gives rise to the LMCA, which bifurcates into the LAD and LCX.

Cardiac Catheterization (CAG) remains the gold standard for accurate assessment of SCA anatomy. Additionally, multislice CTA scanning can generate 3-dimensional imaging showing the anomaly with the advantage of a less invasive method. Additional adjuncts for revealing the degree of ischemia during stress include: the adenosine stress cardiovascular Magnetic Resonance (MR), dobutamine stress MR, ECGgated single-photon emission computed tomography (SPECT), and echocardiography with stress-induced wall motion abnormalities [18-2426].

Because of the rare incidence and the variable anatomy and symptoms encountered, no consensus or guidelines are available, and each case has a specially tailored therapeutic approach. Revascularization is not recommended as a systemic approach, except when it may reverse ischemia, correct a slit-like ostium, reimplant a type III coronary anatomy, or fix a kinked, compressible course.

For group I, medical therapy is generally recommended, as the clinical course is benign. In individual cases with significant atherosclerosis and symptoms, a coronary graft may be necessary. Percutaneous interventions (PCl) have a high risk of ostial dissection and thrombosis [27-30]. Young patients with symptoms of ischemia on exertion should undergo surgery due to the risk of sudden death associated with types
II and III SCAs. The preferred surgery is CABG, along with re-implantation of the abnormal artery to the aorta. Stenotic atherosclerotic lesions also call for CABG to reverse ischemia. Coronary arteries arising from the contralateral coronary sinus without stenotic or slit-like lesions can be reversed surgically by reinsertion into the normal vessels where feasible [31-34].

\section{Conclusion}

SCA is a congenital anatomic abnormality in which only one coronary artery originates from a single coronary ostium in the aortic sinus and supplies the entire myocardium. It is important to recognize this anomaly early on, especially in young adults presenting with symptoms of syncope, weakness, chest pain, or other unexplained, recurrent symptoms. The significant difference in the reported incidence of each type is likely due to the numerous variations in different populations and different inclusion criteria of each study. The majority of the large series looked at patients presenting for coronary angiography with cardiac symptoms, and only a few reports looked at postmortem groups that succumbed to sudden death, particularly young athletes.

The different reports give us a clear idea about who is likely to develop ischemic, nonatherosclerotic symptoms. Those patients with RIIB, LIIB, and RIII seem to be at high risk of developing symptoms during exertion due to compression of the coronary vessels and may benefit from corrective surgery if caught in time.

Cardiologists and cardiovascular surgeons should be aware of this rare condition, which carries a potential risk of sudden cardiac death, especially in young and active adults. The symptoms vary significantly, and some patients may live an uneventful life, while others may be 
prone to catastrophic outcomes. A high index of suspicion and early recognition of a possibly eventful clinical course could save lives.

\section{Acknowledgments}

The authors would like to acknowledge the help of the patient and her family in allowing this publication.

\section{References}

1. Roberts WC. Major anomalies of coronary arterial origin seen in adulthood. Am Heart J. 1986 May;111(5):941-63. doi: 10.1016/0002-8703(86)90646-0. PMID: 3518378 . https://doi.org/10.1016/0002-8703(86)90646-0

2. Lipton MJ, Barry WH, Obrez I, Silverman JF, Wexler L. Isolated single coronary artery: diagnosis, angiographic classification, and clinical significance. Radiology. 1979 Jan;130(1):39-47. doi: 10.1148/130.1.39. PMID: 758666. https://doi.org/10.1148/130.1.39

3. Desmet W, Vanhaecke J, Vrolix M, Van de Werf F, Piessens J, Willems $J$, de Geest $\mathrm{H}$. Isolated single coronary artery: a review of 50,000 consecutive coronary angiographies. Eur Heart J. 1992 Dec;13(12):1637-40. doi: 10.1093/oxfordjournals.eurheartj.a060117. PMID: 1289093.https://doi.org/10.1093/oxfordjournals.eurheartj. a060117

4. Shirani J, Roberts WC. Solitary coronary ostium in the aorta in the absence of other major congenital cardiovascular anomalies. J Am Coll Cardiol. 1993 Jan;21(1):137-43. doi: 10.1016/0735-1097(93)90728-j. PMID: $\quad 8417054$ https://doi.org/10.1016/07351097(93)90728-J

5. Kervancioglu M, Tokel K, Varan B, Yildirim SV. Frequency, origins and courses of anomalous coronary arteries in 607 Turkish children with tetralogy of Fallot. Cardiol J. 2011;18(5):546-51. doi: 10.5603/cj.2011.0011. PMID: 21947991. https://doi.org/10.5603/CJ.2011.0011

6. Yuksel S, Meric M, Soylu K, Gulel O, Zengin H, Demircan S, Yilmaz O, Sahin M. The primary anomalies of coronary artery origin and course: A coronary angiographic analysis of 16,573 patients. Exp Clin Cardiol. 2013 Spring;18(2):121-3. PMID: 23940436; PMCID: PMC3718591.

7. Tuncer C, Batyraliev T, Yilmaz R, Gokce M, Eryonucu B, Koroglu S. Origin and distribution anomalies of the left anterior descending artery in 70,850 adult patients: multicenter data collection. Catheter Cardiovasc Interv. 2006 Oct;68(4):574-85. doi: 10.1002/ccd.20858. PMID: 16969852. https://doi.org/10.1002/ccd.20858

8. Turkmen S, Yolcu M, Sertcelik A, Ipek E, Dokumaci B, Batyraliev T. Single coronary artery incidence in 215,140 patients undergoing coronary angiography. Folia Morphol (Warsz). $2014 \quad$ Nov;73(4):469-74. doi: 10.5603/FM.2014.0070. PMID: 25448905. https://doi.org/10.5603/FM.2014.0070

9. Elbadawi A, Baig B, Elgendy IY, Alotaki E, Mohamed AH, Barssoum K, Fries D, Khan M, Khouzam RN. Single Coronary Artery Anomaly: A Case Report and Review of Literature. Cardiol Ther. 2018 Jun;7(1):119-123. doi: 10.1007/s40119-018-0103-4. Epub 2018 Feb 6. PMID:
29411245;

PMCID:

https://doi.org/10.1007/s40119-018-0103-4

10. Yamanaka O, Hobbs RE. Coronary artery anomalies in 126,595 patients undergoing coronary arteriography. Cathet Cardiovasc Diagn. 1990 Sep;21(1):28-40. doi: 10.1002/ccd.1810210110. PMID: 2208265. https://doi.org/10.1002/ccd.1810210110

11. Braun MU, Stolte D, Rauwolf T, Strasser RH. Single coronary artery with anomalous origin from the right sinus Valsalva. Clin Res Cardiol. 2006 Feb;95(2):119-21. doi: 10.1007/s00392-006-0330-x. Epub 2006 Jan 16. PMID: 16598522. https://doi.org/10.1007/s00392-006-0330-x

12. Shrivastava S, Mohan JC, Mukhopadhyay S, Rajani M, Tandon R. Coronary artery anomalies in tetralogy of Fallot. Cardiovasc Intervent Radiol. 1987;10(4):215-8. doi: 10.1007/BF02593873. PMID: 3115578. https://doi.org/10.1007/BF02593873

13. Antonellis J, Rabaouni A, Kostopoulos K, Margaris N, Kranidis A, Salahas A, Ifantis G, Koroxenidis G. Single coronary artery from the right sinus of Valsalva, associated with absence of left anterior descending and an ostiumsecundum-type atrial septal defect: a rare combination. A case report. Angiology. 1996 Jun;47(6):621-5. doi: 10.1177/000331979604700612. PMID: 8678338. https://doi.org/10.1177/000331979604700612

14. Maron BJ. Sudden death in young athletes. N Engl J Med. $2003 \quad$ Sep 11;349(11):1064-75. doi: 10.1056/NEJMra022783. PMID: 12968091. https://doi.org/10.1056/NEJMra022783

15. Basso C, Maron BJ, Corrado D, Thiene G. Clinical profile of congenital coronary artery anomalies with origin from the wrong aortic sinus leading to sudden death in young competitive athletes. J Am Coll Cardiol. 2000 May;35(6):1493-501. doi: 10.1016/s0735-1097(00)005660. PMID: 10807452. https://doi.org/10.1016/S07351097(00)00566-0

16. Virmani R, Burke AP, Farb A. Sudden cardiac death. Cardiovasc Pathol. 2001 Sep-Oct;10(5):211-8. doi: 10.1016/s1054-8807(01)00091-6. PMID: 11673058 https://doi.org/10.1016/S1054-8807(01)00091-6

17. Sato Y, Inoue F, Kunimasa T, Matsumoto N, Yoda S, Tani S, Takayama T, Uchiyama T, Tanaka H, Furuhashi S, Takahashi M, Koyama Y, Saito S. Diagnosis of anomalous origin of the right coronary artery using multislice computed tomography: evaluation of possible causes of myocardial ischemia. Heart Vessels. 2005 Nov;20(6):298300. doi: 10.1007/s00380-005-0826-8. PMID: 16314914. https://doi.org/10.1007/s00380-005-0826-8

18. Kariofillis P, Mastorakou I, Voudris V. Images in intervention. Origin of right and left coronary arteries from the right sinus of Valsalva as a common coronary trunk. JACC Cardiovasc Interv. 2009 Aug;2(8):805-6. doi: 10.1016/j.jcin.2009.05.021. PMID: 19695552. https://doi.org/10.1016/j.jcin.2009.05.021

19. Taylor AJ, Byers JP, Cheitlin MD, Virmani R. Anomalous right or left coronary artery from the contralateral coronary sinus: "high-risk" abnormalities in the initial coronary artery course and heterogeneous clinical outcomes. Am Heart J. 1997 Apr;133(4):428-35. doi: 10.1016/s0002-8703(97)70184-4. PMID: 9124164. https://doi.org/10.1016/S0002-8703(97)70184-4 
20. Angelini P, Velasco JA, Flamm S. Coronary anomalies: incidence, pathophysiology, and clinical relevance. Circulation. 2002 May 21;105(20):2449-54. doi: 10.1161/01.cir.0000016175.49835.57. PMID: 12021235. https://doi.org/10.1161/01.CIR.0000016175.49835.57

21. Taylor AJ, Rogan KM, Virmani R. Sudden cardiac death associated with isolated congenital coronary artery anomalies. J Am Coll Cardiol. 1992 Sep;20(3):640-7. doi: 10.1016/0735-1097(92)90019-j. $\quad$ PMID: 1512344. https://doi.org/10.1016/0735-1097(92)90019-J

22. Yurtdaş $M$, Gülen $O$. Anomalous origin of the right coronary artery from the left anterior descending artery: review of the literature. Cardiol J. 2012;19(2):122-9. PMID: 22461044. https://doi.org/10.5603/CJ.2012.0023

23. Echavarría-Pinto M, Rodríguez-Rodríguez E, Macías E, Kimura-Hayama E. Extremely rare single right coronary artery: multidetector computed tomography findings. Arch Cardiol Mex. 2012 Apr-Jun;82(2):195-6. PMID: 22735660.

24. Datta J, White CS, Gilkeson RC, Meyer CA, Kansal S, Jani ML, Arildsen RC, Read K. Anomalous coronary arteries in adults: depiction at multi-detector row CT angiography. Radiology. 2005 Jun;235(3):812-8. doi: 10.1148/radiol.2353040314. Epub 2005 Apr 15. PMID: 15833984. https://doi.org/10.1148/radiol.2353040314

25. Yoda S, Sato Y, Matsumoto N, Tani S, Takayama T, Nishina $H$, Uchiyama T, Saito $S$. Incremental value of regional wall motion analysis immediately after exercise for the detection of single-vessel coronary artery disease: study by separate acquisition, dual-isotope ECG-gated single-photon emission computed tomography. Circ J. 2005 Mar;69(3):301-5. doi: 10.1253/circj.69.301. PMID: 15731535. https://doi.org/10.1253/circj.69.301

26. Zhang LJ, Yang GF, Huang W, Zhou CS, Chen P, Lu GM. Incidence of anomalous origin of coronary artery in 1879 Chinese adults on dual-source CT angiography. Neth Heart J. 2010 Oct;18(10):466-70. doi: 10.1007/BF03091817. PMID: 20978590; PMCID: PMC2954298. https://doi.org/10.1007/BF03091817

27. Rudan D, Todorovic N, Starcevic B, Raguz M, Bergovec M. Percutaneous coronary intervention of an anomalous right coronary artery originating from the left coronary artery. Wien Klin Wochenschr. 2010 Aug;122(1516):508-10. doi: 10.1007/s00508-010-1420-3. Epub 2010 Aug 2. PMID: 20676783. https://doi.org/10.1007/s00508010-1420-3

28. Calişkan M, Ciftçi O, Güllü H, Alpaslan M. Anomalous right coronary artery from the left sinus of Valsalva presenting a challenge for percutaneous coronary intervention. Turk Kardiyol Dern Ars. 2009 Jan;37(1):44-7. PMID: 19225253.

29. Kafkas N, Triantafyllou K, Babalis D. An isolated single L-I type coronary artery with severe LAD lesions treated by transradial PCl. J Invasive Cardiol. 2011 Sep;23(9):E2168. PMID: 21891816.

30. lio K, Nandate H, Nakamura T, Nakashima Y, Kuroiwa A. The study of a case of single coronary artery using stress 201thalium single photon emission computed tomogram. J UOEH. 1989 Mar 1;11(1):55-62. doi: 10.7888/juoeh.11.55. 2497506. https://doi.org/10.7888/juoeh.11.55
31. Said SA, de Voogt WG, Bulut S, Han J, Polak P, Nijhuis $\mathrm{RL}$, Op den Akker JW, Slootweg A. Coronary artery disease in congenital single coronary artery in adults: A Dutch case series. World J Cardiol. 2014 Apr 26;6(4):196204. doi: 10.4330/wjc.v6.i4.196. PMID: 24772259; PMCID: PMC3999339. https://doi.org/10.4330/wjc.v6.i4.196

32. Frescura C, Basso C, Thiene G, Corrado D, Pennelli T, Angelini A, Daliento L. Anomalous origin of coronary arteries and risk of sudden death: a study based on an autopsy population of congenital heart disease. Hum Pathol. 1998 Jul;29(7):689-95. doi: 10.1016/s00468177(98)90277-5. PMID: 9670825. https://doi.org/10.1016/S0046-8177(98)90277-5

33. Rinaldi RG, Carballido J, Giles R, Del Toro E, Porro R. Right coronary artery with anomalous origin and slit ostium. Ann Thorac Surg. 1994 Sep;58(3):829-32. doi: 10.1016/0003-4975(94)90760-9. PMID: 7944711. https://doi.org/10.1016/0003-4975(94)90760-9

34. Izumiyama O, Yamashita A, Sugimoto S, Baba M, Hasegawa T. [Coronary artery bypass grafting in two patients with single coronary artery]. Kyobu Geka. 1999 Feb;52(2):143-7. Japanese. PMID: 10036876.

35. Neiva J, Passos Silva M, Pires-Morais G, Dias A, Ponte M, Caeiro D, Braga JP, Ferreira N, Ribeiro V. Right single coronary artery as an incidental finding in Takotsubo syndrome and acute heart failure: Case report and review of the literature. Rev Port Cardiol. 2019 Mar;38(3):215-223. English, Portuguese. doi: 10.1016/j.repc.2018.06.013. Epub 2019 Apr 20. PMID: 31014998 https://doi.org/10.1016/j.repc.2018.06.013 